\title{
Original Article \\ Changes of Blood Flow Volume in the Superior Mesenteric Artery and Brachial Artery with Abdominal Thermal Stimulation
}

\author{
Shin Takayama, ${ }^{1}$ Takashi Seki, ${ }^{1}$ Masashi Watanabe, ${ }^{1}$ Shigeru Takashima, ${ }^{2}$ Norihiro Sugita, ${ }^{3}$ \\ Satoshi Konno, ${ }^{4}$ Takashi Takeda, ${ }^{1}$ Hiroyuki Arai, ${ }^{4}$ Tomoyuki Yambe, ${ }^{4}$ Nobuo Yaegashi, ${ }^{1}$ \\ Makoto Yoshizawa, ${ }^{5}$ Shigenao Maruyama, ${ }^{2}$ and Shin-Ichi Nitta ${ }^{4}$ \\ ${ }^{1}$ Center for Asian Traditional Medicine, Graduate School of Medicine, Tohoku University, Miyagi, Japan \\ ${ }^{2}$ Institute of Fluid Science, Tohoku University, Miyagi, Japan \\ ${ }^{3}$ Department of Electrical and Communication Engineering, Graduate School of Engineering, \\ Tohoku University, Miyagi, Japan \\ ${ }^{4}$ Institute of Development, Aging and Cancer, Tohoku University, Miyagi, Japan \\ ${ }^{5}$ Research Division on Advanced Information Technology, Cyberscience Center, Tohoku University, Miyagi, Japan
}

Correspondence should be addressed to Takashi Seki, tseki.tohoku@gmail.com

Received 18 November 2008; Accepted 17 July 2009

Copyright (C) 2011 Shin Takayama et al. This is an open access article distributed under the Creative Commons Attribution License, which permits unrestricted use, distribution, and reproduction in any medium, provided the original work is properly cited.

\begin{abstract}
In traditional Chinese medicine, moxibustion is a local thermal therapy that is used for several conditions. Quantifying the effects of moxibustion therapy has been difficult because the treatment temperature depends on the physician's experience, and the temperature distribution in the target area is not uniform. This prospective observational study aims to quantify the effect of local thermal stimulation to the abdomen. We developed a heat transfer control device (HTCD) for local thermal stimulation. Twenty-four healthy subjects were enrolled and they underwent abdominal thermal stimulation to the para-umbilical region with the device for $20 \mathrm{~min}$. Blood flow volume in the superior mesenteric artery (SMA) and brachial artery (BA), the heart rate and the blood pressure were measured at rest, 15 min after starting thermal stimulation and 10, 20, 30 and 40 min after completing thermal stimulation. Blood flow parameters were measured by high-resolution ultrasound. In the SMA, blood flow volume was significantly increased during thermal stimulation $(P<.01)$, as well as at $10 \mathrm{~min}(P<.01)$ and $20 \mathrm{~min}(P<.05)$ after stimulation. In the BA, blood flow volume decreased at $40 \mathrm{~min}$ after stimulation $(P<.01)$. In conclusion we could quantify the effect of local thermal stimulation with an HTCD and high-resolution ultrasound. Thermal stimulation of the para-umbilical region increased blood flow in the SMA 20 min after stimulation in healthy subjects.
\end{abstract}

\section{Introduction}

Recently, thermal therapy has been used for a number of conditions such as inflammatory bowel diseases, chronic heart failure, chronic pain, depressive state and chronic obstructive pulmonary disease [1-13]. It can be classified into two types: one type involves heating the whole body or a large part of it in a sauna or warm bath. This procedure has been shown to reduce cardiac after-load and pre-load and to increase cardiac function in patients with chronic heart failure $[4-6,12]$. The other type involves heating of a local body area. Local thermal therapy with a hot pack or paraffin has often been used to treat pain [8]. It has been reported that local thermal therapy reduces myotonia, improves the circulation and relieves pain by accelerating the removal of pain-producing substances. In traditional Chinese medicine, a local thermal therapy known as moxibustion is widely used for several conditions such as pain, nausea, vomiting, neurodegenerative diseases, inflammatory bowel diseases and cerebrovascular and cardiovascular diseases [14-16]. Moxibustion is the way of heating a local area in which moxa is burned at acupoints on the skin. Because the direct burning of moxa on the skin can be dangerous, materials like salt, ginger or garlic may be used as a buffer between the skin and the moxa. Several previous studies have assessed the effect of moxibustion [1-3, 17], but controlling the temperature achieved by moxibustion has been difficult. The actual temperature depends on the physician's experience 


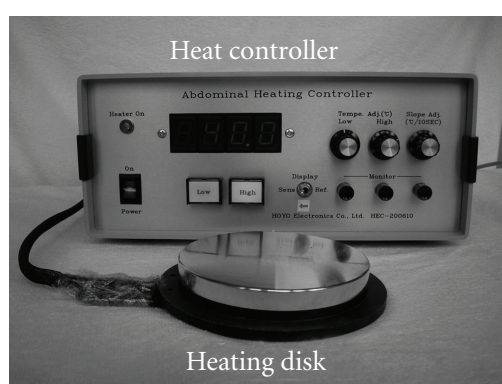

FIGURE 1: HTCD is composed of a heating disk, temperature sensor and a heat controller.

and the temperature distribution in the target area is not uniform. Therefore, we developed the heat transfer control device (HTCD) used in the present study.

Under normal conditions, the superior mesenteric artery (SMA) blood flow pattern and velocity show large variations due to the metabolic activity of the bowel [18-20]. The SMA blood flow volume also changes in several diseases [21-23]. The blood flow volume is also strongly related to mesenteric ischemia, especially chronic mesenteric ischemia [24].

There have been no reports about SMA blood flow changes in relation to moxibustion therapy. Therefore, this study was performed to evaluate the changes of SMA blood flow volume with abdominal ultrasound after thermal stimulation with an HTCD.

\section{Methods}

2.1. Subjects. We enrolled 24 healthy male subjects, who had a mean \pm SD age of $31.2 \pm 6.9$ years (range $21-44$ years). The study protocol was approved by the Ethics Committee of Tohoku University Graduate School of Medicine. Written informed consent to participation was given by all subjects.

2.2. Thermal Stimulation Method. To quantify the heat delivered, we developed an HTCD instead of moxibustion for local thermal stimulation (Figure 1) [25]. This device was composed of a heating disk $(10 \mathrm{~cm}$ in diameter), a temperature sensor and a heat controller. The temperature of the heating disk could be increased incrementally to the target and would not exceed it. We could control the temperature of the heating disk with a precision of $0.1^{\circ} \mathrm{C}$ and the device heated a small region to a uniform temperature. Therefore, it was suitable to quantify the effect of thermal stimulation. Thermal damage occurs when the tissue temperature rises above $44^{\circ} \mathrm{C}[26,27]$, so the temperature of the disk was set at $40-41^{\circ} \mathrm{C}$ for safety. A patent for this device is pending in Japan.

2.3. Study Protocol. This is a prospective observational study. We performed abdominal thermal stimulation at the paraumbilical region with an HTCD for 20 min and measured SMA hemodynamics by ultrasound from rest until $40 \mathrm{~min}$ after thermal stimulation. To compare intestinal and peripheral blood flow volume, we measured the hemodynamics of the brachial artery (BA) simultaneously. An outline of the study is shown in Figure 2.

All subjects were examined in the morning after an overnight fast (at least $8 \mathrm{~h}$ ). The subject rested in the supine position in a quiet, air-conditioned room (temperature 25$26^{\circ} \mathrm{C}$ ). Three monitoring electrocardiographic electrodes were attached to the chest. Blood pressure was measured in the left upper arm with an oscillometer (HEM-9000AI, Omron Healthcare Co., Ltd, Kyoto, Japan). SMA and right BA hemodynamics were measured with an ultrasound system (Prosound $\alpha 10$, Aloka Co., Ltd, Tokyo, Japan). Highresolution ultrasound combined with pulsed Doppler is useful to investigate small vessels, such as the coronary, splenic, adrenal and SMA [28]. The present ultrasound system had a $5 \mathrm{MHz}$ convex transducer and a $13 \mathrm{MHz}$ linear transducer. We used the convex transducer to measure SMA hemodynamics and the linear transducer for BA hemodynamics. The cross-sectional areas (CSAs) of the SMA and $\mathrm{BA}$ were calculated by vessel diameter (VD), the distance from anterior to posterior intima (Figures 3(a) and 3(c)). As described earlier, SMA measurements were acquired within $2-3 \mathrm{~cm}$ of the origin of the artery (Figure $3(\mathrm{~b}))[29,30]$. Pulsed Doppler signals were obtained at the same site. The BA was monitored at a site above the elbow (Figure 3(d)). For accurate measurement, a Doppler angle of $60^{\circ}$ or less was employed [31, 32]. Each Doppler waveform was drawn automatically and calculated by using the software in the ultrasound system. The following hemodynamic parameters were determined.

Hemodynamic parameters:

(i) $\mathrm{VD}$

(ii) $\mathrm{CSA}=(\mathrm{VD} / 2)^{2} \times \pi$

(iii) Peak systolic velocity (PSV)

(iv) End-diastolic velocity (EDV)

(v) Resistive index (RI) $=(\mathrm{PSV}-\mathrm{EDV}) / \mathrm{PSV}$

(vi) Pulsatility index $(\mathrm{PI})=(\mathrm{PSV}-\mathrm{EDV}) / \mathrm{MV}$

(vii) Mean flow velocity (MV)

(viii) Blood flow volume $=\mathrm{CSA} \times \operatorname{MV}[29,30]$

Each parameter was recorded three times in three different cardiac cycles and averaged for each subject in an effort to minimize random errors [29].

After positioning the ultrasound system, the subjects rested in the supine position for $10 \mathrm{~min}$. Abdominal thermal stimulation was done at the para-umbilical region with the $\mathrm{HTCD}$ for $20 \mathrm{~min}$ from a temperature of $40^{\circ} \mathrm{C}$. After $5 \mathrm{~min}$, if subjects were used to the heat, the temperature was increased to $41^{\circ} \mathrm{C}$. After thermal stimulation for $20 \mathrm{~min}$, the device was removed.

We measured the SMA and BA hemodynamics, heart rate and blood pressure at rest (baseline), after $15 \mathrm{~min}$ of thermal stimulation, and 10, 20, 30 and $40 \mathrm{~min}$ after the end of thermal stimulation (Figure 2).

2.4. Statistical Analysis. Statistical analysis was performed with SPSS software (version 16.0, SPSS Japan Inc., Tokyo, 


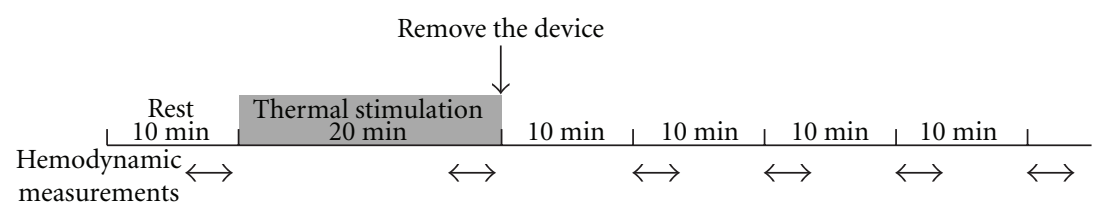

FIgURE 2: Outline of the study. Thermal stimulation was applied to the para-umbilical region with an HTCD for 20 min. Hemodynamics were measured at rest (baseline), during thermal stimulation (after $15 \mathrm{~min}$ ) and at 10, 20, 30 and $40 \mathrm{~min}$ after the completion of thermal stimulation.

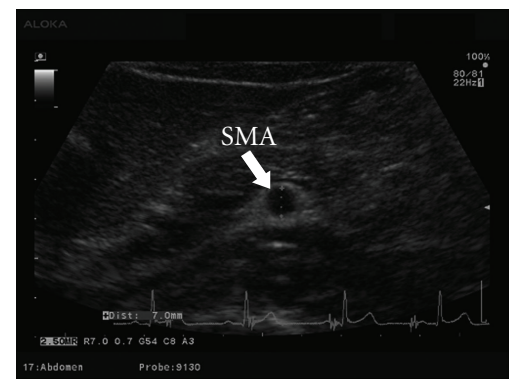

(a)

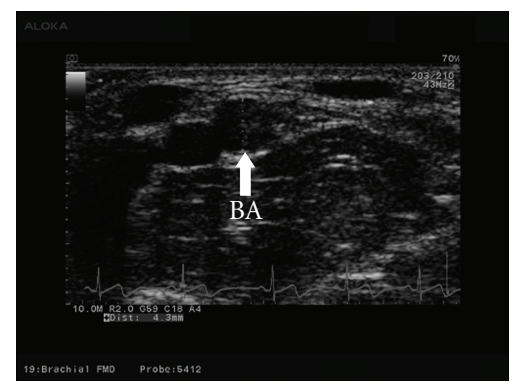

(c)

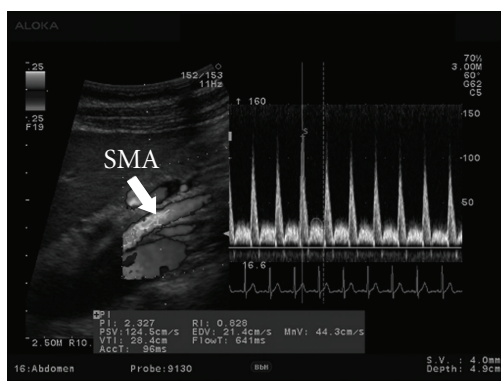

(b)

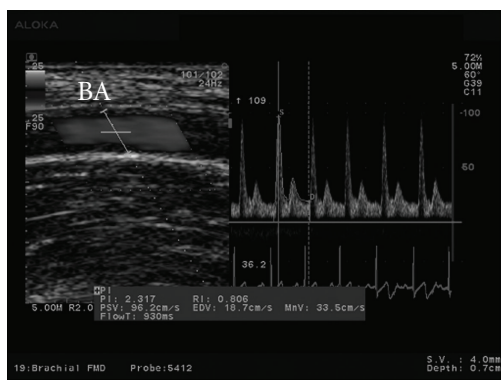

(d)

Figure 3: Hemodynamic data obtained by ultrasound. (a) VD of the SMA, (b) blood flow velocity of the SMA, (c) vessel diameter of the BA and (d) blood flow velocity of the BA.

Japan). Repeated measures analysis of variance with a Tukey post hoc test was used for statistical comparison with baseline. Although 24 subjects were enrolled in our study, three subjects were excluded because their examinations were technically unsuccessful (the SMA could not be identified clearly due to intestinal gas). As a result, 21 subjects were included in the final analysis. Results are presented as the medians and quartile (first and third), the means and SEM and $95 \%$ confidence intervals. $P<.05$ was used to indicate significance in all statistical tests.

\section{Results}

3.1. Hemodynamic Parameters in the SMA and BA. The hemodynamic parameters in the SMA and BA are summarized in Tables 1 and 2 .

The changes of VD, MV and blood flow volume in the SMA and BA are shown in Figures 4(a) and 5(a), 4(b) and 5(b) and 4(c) and 5(c), respectively. The SMA diameter significantly increased during thermal stimulation $(P<.01)$, as well as at $10 \mathrm{~min}(P<.01), 20 \mathrm{~min}(P<.01)$ and
$30 \min (P<.05)$ after thermal stimulation (Figure 4(a)). The BA diameter also increased significantly during thermal stimulation $(P<.01)$ and at $20 \mathrm{~min}(P<.05)$ after thermal stimulation (Figure 5(a)). The MV in the SMA showed significant increase during thermal stimulation $(P<$ $.01)$, as well as at $10 \mathrm{~min}(P<.01)$ and $20 \mathrm{~min}(P<$ .01 ) after the end of thermal stimulation (Figure $4(\mathrm{~b})$ ), but the flow velocity in the BA significantly decreased at $30 \mathrm{~min}(P<.01)$ and $40 \mathrm{~min}(P<.01)$ after thermal stimulation (Figure 5(b)). The blood flow volume in the SMA significantly increased during thermal stimulation $(P<$ $.01)$, as well as at $10 \mathrm{~min}(P<.01)$ and $20 \mathrm{~min}(P<.05)$ after the end of thermal stimulation (Figure $4(\mathrm{c})$ ). In the BA, however, blood flow volume decreased at $40 \mathrm{~min}$ after the end of thermal stimulation $(P<.01)$ (Figure $5(\mathrm{c})$ ).

PSV in the SMA showed a significant increase during thermal stimulation $(P<.01)$ (Table 1$)$, but while it significantly decreased in the BA at $30 \mathrm{~min}(P<.05)$ and $40 \min (P<.01)$ after the end of thermal stimulation (Table 2). EDV did not change in the SMA (Table 1), but it decreased significantly at $30 \mathrm{~min}(P<.01)$ and $40 \mathrm{~min}$ 


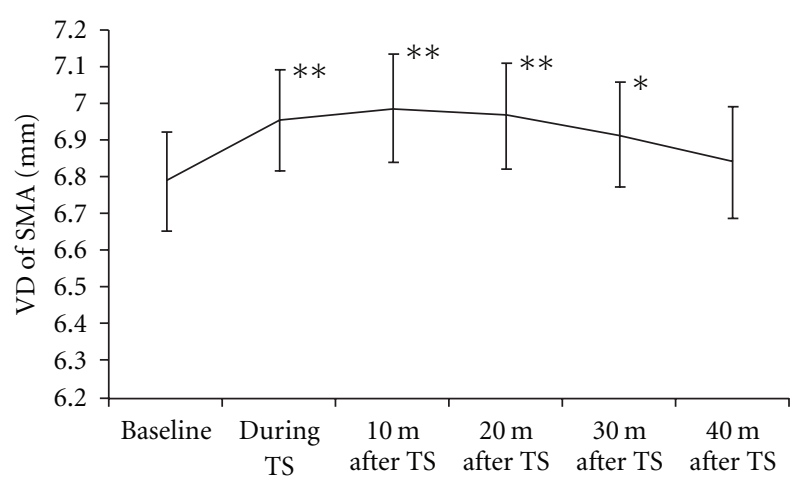

(a)

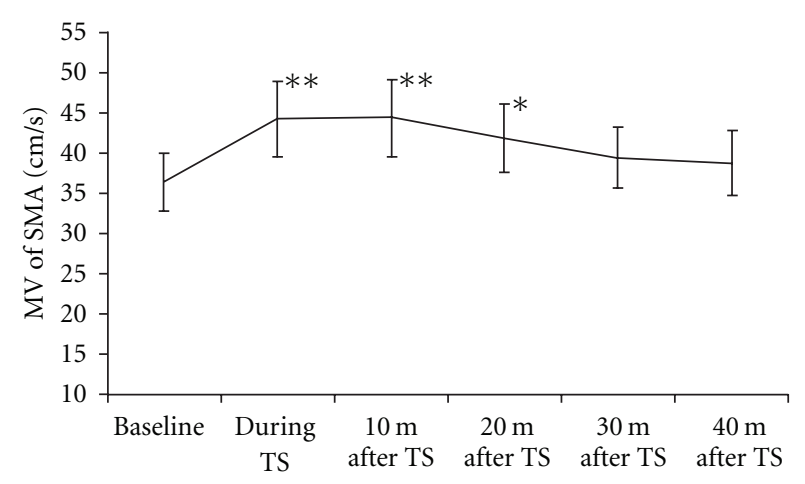

(b)

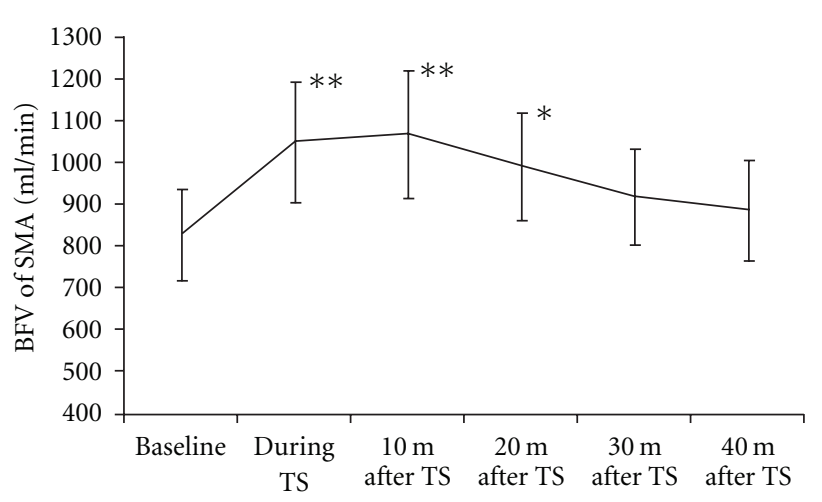

(c)

FIgUre 4: Hemodynamic changes in the SMA. (a) Change of vessel diameter, (b) change of MV and (c) change of blood flow volume. The values represent the means and SEM. ${ }^{*} P<.05,{ }^{* *} P<.01$ versus baseline.

$(P<.01)$ after the end of thermal stimulation in the BA (Table 2). The RI in the SMA did not change (Table 1), but it significantly increased in the BA at $40 \mathrm{~min}$ after the end of thermal stimulation $(P<.01)$ (Table 2$)$. However, the PI showed no significant changes in the SMA and BA compared with baseline (Tables 1 and 2).

3.2. Systemic Hemodynamics. The blood pressure and heart rate are shown in Table 3 . There were no significant changes of heart rate compared with baseline. Systolic blood pressure showed a significant increase at $40 \mathrm{~min}$ after the end of thermal stimulation $(P<.05)$, but there no significant changes in diastolic blood pressure was observed between baseline and $40 \mathrm{~min}$ after thermal stimulation.

3.3. Side Effects of Abdominal Thermal Stimulation. There were no complications such as local burns, pain, discomfort or other problems that needed treatment.

\section{Discussion}

This is the first report about the changes of blood flow volume for SMA and BA by local thermal stimulation with an ultrasound system. In SMA, blood flow volume significantly increased during thermal stimulation, as well as at 10 and $20 \mathrm{~min}$ after stimulation. In BA, blood flow volume significantly decreased $40 \mathrm{~min}$ after stimulation.

We expressed the changes of SMA hemodynamics with an ultrasound system. The SMA supplies blood to the duodenum, small bowel, colon and rectum. Blood flow volume in the SMA can be altered by several diseases, such as Crohn's disease, ulcerative colitis, enteroperitoneal tuberculosis and appendicitis [21-23, 28]. Blood flow volume is also altered in mesenteric ischemia, with chronic mesenteric ischemia being closely related to SMA blood flow [24]. After meals, there is an increase of mesenteric blood flow to assist digestion [20] and vasodilation allows more blood flow into the intestines. The pulsed Doppler method has been used to assess rapid changes of hemodynamics in the SMA. The blood flow volume increases significantly after food intake, whereas exercise reduces mesenteric blood flow in normal subjects $[20,33]$. Various vasoconstrictive stimuli, including mental arithmetic, cold, isometric exercise and head-up tilt also influence the SMA diameter and blood flow volume [34]. However, it has not been previously shown that SMA blood flow volume is increased by local thermal stimulation. Uchida et al. [35] investigated the mechanisms by which blood flow was increased in the internal organs by acupuncture. They suggested that the increase of uterine blood flow with acupuncture was mediated by a segmental spinal reflex mechanism that involved excitation of somatic group II, III and IV afferents and pelvic parasympathetic cholinergic nerves. It has been reported that several acupoints have an influence on the gastrointestinal motility [36], which is thought to be mediated via parasympathetic nerves $[37,38]$. Thermal stimulation of the para-umbilical region simultaneously stimulates multiple acupoints related to the intestine by thermal energy and mechanical pressure. There are several acupoints (including CV-7, CV-8, CV9 and ST-25) located at the para-umbilical region where we performed abdominal thermal stimulation. In particular, CV-8 and ST-25 are considered to influence the stomach, spleen and intestine in traditional Chinese medicine [39]. Thermal stimulation and pressure applied to the skin by the present method influences somatic afferent fibers. Thus, we speculate that the present method of stimulation increase SMA blood flow mediated by somatic group II, III and IV afferent fibers and parasympathetic cholinergic nerves. Our 
TABLE 1: Summary of hemodynamic parameters.

\begin{tabular}{|c|c|c|c|c|c|c|}
\hline Parameter & Baseline & During TS & 10 min after TS & 20 min after TS & $30 \mathrm{~min}$ after TS & 40 min after TS \\
\hline \multicolumn{7}{|l|}{$\mathrm{VD}(\mathrm{mm})$} \\
\hline Median (first, third quartile) & $6.87(6.4,7.17)$ & $7.0(6.67,7.3)$ & $7.05(6.65,7.53)$ & $7.13(6.7,7.47)$ & $7.0(6.6,7.2)$ & $6.97(6.55,7.3)$ \\
\hline Mean (SEM) & $6.79(0.14)$ & $6.69(0.14)^{* *}$ & $7.01(0.15)^{* *}$ & $6.97(0.15)^{* *}$ & $6.92(0.14)^{*}$ & $6.84(0.15)$ \\
\hline $95 \% \mathrm{CI}$ & $6.52-7.06$ & $6.69-7.23$ & $6.70-7.28$ & $6.68-7.26$ & $6.64-7.20$ & $6.55-7.14$ \\
\hline \multicolumn{7}{|l|}{$\operatorname{PSV}(\mathrm{cm} / \mathrm{s})$} \\
\hline Median (first, third quartile) & $\begin{array}{c}144.3 \\
(121.3,168.2)\end{array}$ & $\begin{array}{c}163.3 \\
(146.3,194.2)\end{array}$ & $\begin{array}{c}166.7 \\
(149.6,191.7)\end{array}$ & $\begin{array}{c}153.4 \\
(139.6,205.7)\end{array}$ & $\begin{array}{c}156.75 \\
(132.5,181.8)\end{array}$ & $\begin{array}{c}156.4 \\
(134.8,192.6)\end{array}$ \\
\hline Mean (SEM) & $151.3(9.1)$ & $178.3(1.04)^{* *}$ & $170.0(12.1)$ & $169.8(9.8)$ & $162.4(9.7)$ & $161.2(8.5)$ \\
\hline $95 \%$ CI & $133.5-169.1$ & 157.9-198.8 & $146.4-193.7$ & $150.6-189.1$ & $143.4-181.4$ & $145.0-177.6$ \\
\hline \multicolumn{7}{|l|}{$\operatorname{EDV}(\mathrm{cm} / \mathrm{s})$} \\
\hline Median (first, third quartile) & $6.5(1.35,13.9)$ & $10.7(5.9,15.8)$ & $8.7(2.2,13.2)$ & $9.9(0.3,14.7)$ & $6.6(0.0,14.8)$ & $7.4(0.0,13.6)$ \\
\hline Mean (SEM) & $10.7(2.7)$ & $14.9(3.7)$ & $12.3(3.8)$ & $12.0(3.2)$ & $10.5(2.8)$ & $11.0(3.1)$ \\
\hline $95 \% \mathrm{CI}$ & $5.3-16.2$ & $7.6-22.1$ & $4.9-19.7$ & $5.8-18.3$ & $5.0-16.0$ & $5.1-17.0$ \\
\hline \multicolumn{7}{|l|}{ RI } \\
\hline Median (first, third quartile) & $1(0.94,1.04)$ & $0.98(0.92,1.00)$ & $0.96(0.92,1.00)$ & $0.97(0.93,1.00)$ & $1(0.92,1.00)$ & $0.98(0.92,1.00)$ \\
\hline Mean (SEM) & $0.98(0.02)$ & $0.96(0.02)$ & $0.95(0.01)$ & $0.96(0.02)$ & $0.97(0.02)$ & $0.96(0.02)$ \\
\hline $95 \% \mathrm{CI}$ & $0.95-1.01$ & $0.92-1.00$ & $0.92-0.98$ & $0.93-0.99$ & $0.94-1.00$ & $0.93-0.99$ \\
\hline \multicolumn{7}{|l|}{ PI } \\
\hline Median (first, third quartile) & $4.57(3.00,5.26)$ & $4(3.41,4.93)$ & $3.98(3.23,4.83)$ & $3.84(3.43,4.99)$ & $4.16(3.48,4.95)$ & $4(3.39,5.35)$ \\
\hline Mean (SEM) & $4.29(0.40)$ & $4.21(0.28)$ & $4.11(0.26)$ & $4.30(0.29)$ & $4.30(0.27)$ & $4.36(0.32)$ \\
\hline $95 \% \mathrm{CI}$ & $3.51-5.07$ & $3.66-4.76$ & $3.60-4.61$ & $3.73-4.87$ & $3.77-4.84$ & $3.74-4.98$ \\
\hline \multicolumn{7}{|l|}{$\mathrm{MV}(\mathrm{ml} / \mathrm{s})$} \\
\hline Median (first, third quartile) & $34.4(28.5,38.6)$ & $39.8(34.2,44.3)$ & $38.6(31.7,45.7)$ & $36.7(30.1,46.4)$ & $33.5(29.5,41.3)$ & $33.5(28.9,38.7)$ \\
\hline Mean (SEM) & $36.6(3.6)$ & $44.5(4.6)^{* *}$ & $44.6(4.8)^{* *}$ & $42.0(4.3)^{*}$ & $49.66(3.7)$ & $39.0(3.9)$ \\
\hline $95 \% \mathrm{CI}$ & $29.6-43.7$ & $35.5-53.5$ & $35.1-54.1$ & $33.6-50.3$ & $32.3-47.0$ & $31.5-46.6$ \\
\hline \multicolumn{7}{|l|}{$\mathrm{BFV}(\mathrm{ml} / \mathrm{min})$} \\
\hline Median (first, third quartile) & $\begin{array}{c}747.1 \\
(565.1,891.6)\end{array}$ & $\begin{array}{c}814 \\
(755.0,1066.7)\end{array}$ & $\begin{array}{c}847.3 \\
(684.6,1098.8)\end{array}$ & $\begin{array}{c}827.7 \\
(633.7,1058.7)\end{array}$ & $\begin{array}{c}818 \\
(566.0,960.3)\end{array}$ & $\begin{array}{c}751.6 \\
(577.5,859.3)\end{array}$ \\
\hline Mean (SEM) & $822.1(109.3)$ & $\begin{array}{c}1045.0 \\
(143.5)^{* *}\end{array}$ & $\begin{array}{c}1062.8 \\
(153.6)^{* *}\end{array}$ & $986.3(129.8)^{*}$ & $913.7(11.7)$ & $882.1(119.3)$ \\
\hline $95 \% \mathrm{CI}$ & $623.7-1020.4$ & $784.6-1035.4$ & $784.1-1341.6$ & $750.8-1221.8$ & $711.0-116.3$ & $671.7-1092.5$ \\
\hline
\end{tabular}

Hemodynamic parameters measured by ultrasound are shown for the SMA. The values represent medians and quartile (first and third), means and SEM and $95 \%$ CI. TS, thermal stimulation; BFV, blood flow volume. ${ }^{*} P<.05,{ }^{* *} P<.01$ versus baseline.

hypothesis for the mechanism of increase of blood flow volume in SMA by HTCD is shown in Figure 6.

The SMA blood flow reflects mesenteric flow, whereas BA blood flow reflects peripheral flow. The present study showed that the blood flow volume of the SMA increased significantly during thermal stimulation and up to $20 \mathrm{~min}$ after thermal stimulation, while it decreased $40 \mathrm{~min}$ after thermal stimulation in the BA. According to the blood flow velocity curve of the SMA and BA, the interarterial differences of blood pressure between SMA and BA can be calculated. The difference significantly increased during thermal stimulation (95\% confidence interval $(95 \% \mathrm{CI}) 0.5-$ $3.9 \mathrm{mmHg} ; P<.01)$, at $10 \mathrm{~min}(95 \% \mathrm{CI} 0.3-3.6 ; P<.01)$ and 20 min $(95 \%$ CI $0.17-3.6 ; P<.05)$ after thermal stimulation compared with baseline. Thus, we can speculate that the interarterial difference of blood pressure is one of the causes of the shift in blood volume. Tsuru et al. suggested that acupuncture causes vasodilation and increases blood flow in various organs by modulating the central circulatory system and axon reflexes, with the effect depending on the site of stimulation [40]. It seems that the SMA (near the stimulated area) was influenced by a vasodilatory action, while the BA (distant from the stimulated area) was little influenced by that mechanism (Figure 6). Vasomotor regulation of blood VD induces changes in blood flow. In the extremities, vasoconstriction is more important than active vasodilatation to regulate the systemic circulation [41]. Vasomotor function in the hand is mainly controlled by sympathetic nerves [ $[42,43]$, and it has been reported that the distribution of vasodilator neurons is not uniform and that the neurons innervating vascular beds perform different functions [44]. Thus, there are the difference of the distribution of vasoconstrictor and 


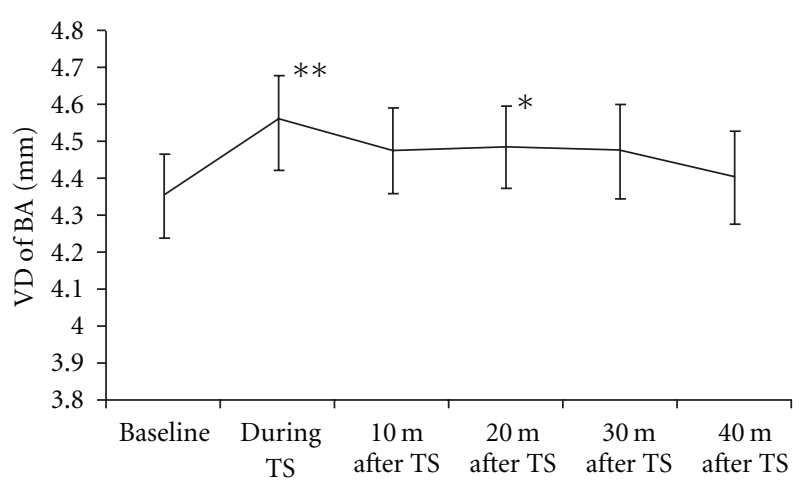

(a)

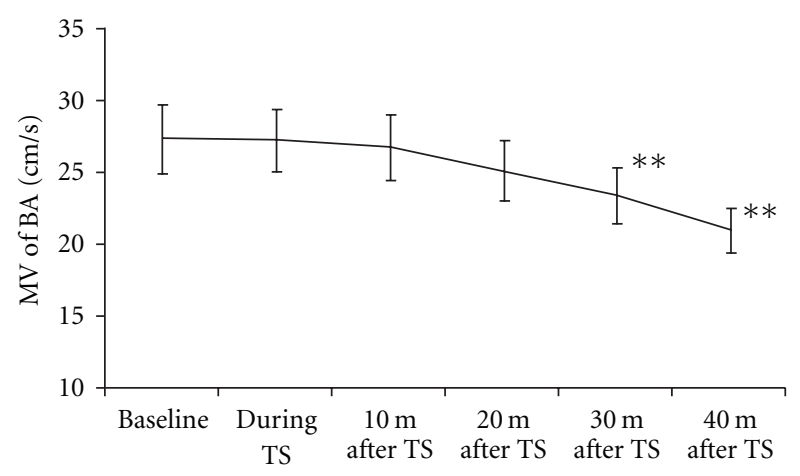

(b)

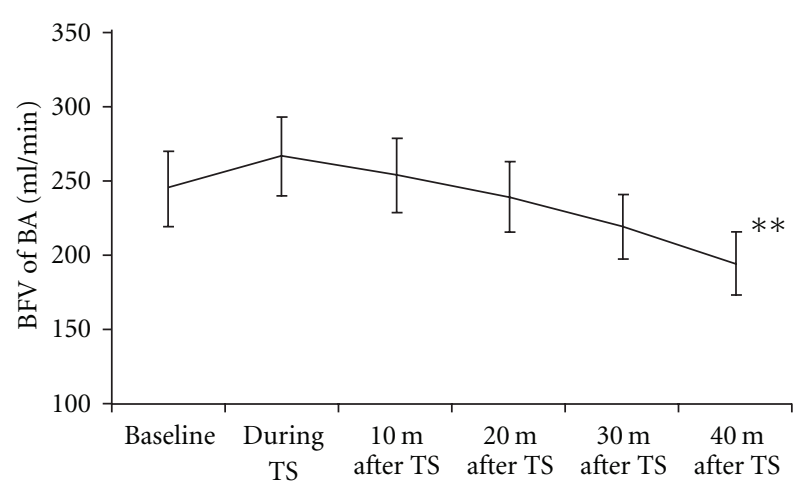

(c)

Figure 5: Hemodynamic changes in the BA. (a) Change of vessel diameter, (b) change of mean flow velocity and (c) change of blood flow volume. The values represent the means and SEM. ${ }^{*} P<.05$, ** $P<.01$ versus baseline.

vasodilator neurons between SMA and BA. The difference in blood flow volume changes between the SMA and BA may be also related to the different distribution of these neurons (Figure 6).

Our hypothesis is that the change of blood flow volume by thermal stimulation with HTCD is related not to the direct thermal energy, but to the reaction of vasodilator neurons. The thermal energy in the skin is continuously carried off by blood circulation in the skin, fat and muscles in the human body. An increase in the tissue temperature causes an activation of the metabolism. The increase in the metabolism and subsequent increase in perfusion due to increasing temperatures are modeled according to a wellknown $Q_{10}$ relation of thermal physiology [45]. This relation states that for every $10^{\circ} \mathrm{C}$ increase in tissue temperature, there is a corresponding increase in cell metabolism and blood flow with a constant factor $Q_{10}$ [46]:

$$
\begin{gathered}
\omega_{b}(T)=\omega_{0} Q_{10}^{\left(T-T_{a}\right) / 10} \\
\dot{q}_{\text {met }}(T)=\dot{q}_{0} Q_{10}^{\left(T-T_{a}\right) / 10}
\end{gathered}
$$

where $T\left({ }^{\circ} \mathrm{C}\right)$ is the temperature, $T_{a}$ is the temperature at artery, $\omega_{b}\left(\mathrm{~s}^{-1}\right)$ is the blood flow rate of a tissue, $q_{\text {met }}$ is metabolic heat generation. $\omega_{0}$ is the perfusion rate under normal condition at $T_{0}$, and $q_{0}$ is the metabolic heat generation under normal condition. To clarify whether thermal stimulation can heat the internal organ directly, we previously analyzed the distribution of temperature in the subcutaneous tissue [47]. In most bioheat transfer analysis, a continuous model proposed by Pennes is widely used. The model is given by [48]:

$$
\begin{aligned}
\rho c \frac{\partial T}{\partial t}= & \frac{1}{r} \frac{\partial}{\partial r}\left(k r \frac{\partial T}{\partial r}\right)+\frac{\partial}{\partial z}\left(k \frac{\partial T}{\partial z}\right) \\
& +\rho_{b} c_{b} \omega_{b}(T)\left(T_{a}-T\right)+\dot{q}_{\mathrm{met}}(T),
\end{aligned}
$$

where $\rho\left(\mathrm{kg} \mathrm{m}^{-3}\right)$ is density, $c\left(\mathrm{~J} \mathrm{~kg}^{-1}{ }^{\circ} \mathrm{C}^{-1}\right)$ is specific heat, $k\left(\mathrm{~W} \mathrm{~m}-1{ }^{\circ} \mathrm{C}^{-1}\right)$ is thermal conductivity, $t$ (s) is time and subscript b expresses blood. The expression on the left means a change in temperature. The first to third expressions on the right show heat conduction and heat exchange between blood and tissue, while the fourth shows metabolic heat generation. We developed a model to analyze the distribution of temperature achieved with local thermal stimulation and this model was composed of a skin layer $(0.4 \mathrm{~mm})$, a fat layer $(7.8 \mathrm{~mm})$ and a muscle layer $(13.4 \mathrm{~mm})$ [49]. Our analysis indicated that heat was almost dissipated in the lipid layer and little heat penetrates to the internal organs. Thus, if we heat the surface of the abdomen to $42^{\circ} \mathrm{C}$ for $15 \mathrm{~min}$, the intestine is not heated directly. Therefore, the blood flow volume increase observed with the local thermal stimulation is not simply due to the transfer of thermal energy, but due to the fact that heat stimulation leads to hemodynamic changes.

In the present study, we demonstrated the change of blood flow volume by HTCD. To our knowledge, this is the first report about the effect of abdominal thermal stimulation on blood flow in the SMA and BA. This trial was a pilot study with a small sample size, and no control and randomization. The subjects were all men. However, the pattern of change of blood flow volume in SMA and BA was same in the subjects, except for one. We supposed that the blood flow volume did not occur by chance. We would like to undertake this study further in both men and women, with a larger sample size, control group and randomization.

Mesenteric ischemia results from decreased blood flow to the bowel, causing several symptoms such as pain, nausea and vomiting. Non-occlusive mesenteric ischemia is an acute mesenteric circulatory disorder which is induced 
TABLE 2: Summary of hemodynamic parameters.

\begin{tabular}{|c|c|c|c|c|c|c|}
\hline Parameter & Baseline & During TS & 10 min after TS & 20 min after TS & 30 min after TS & 40 min after TS \\
\hline \multicolumn{7}{|l|}{$\mathrm{VD}(\mathrm{mm})$} \\
\hline $\begin{array}{l}\text { Median (first, } \\
\text { third quartile) }\end{array}$ & $4.4(3.85,4.6)$ & $4.6(4.0,4.8)$ & $4.47(4.07,4.77)$ & $4.45(4.0,4.73)$ & $4.55(3.87,4.7)$ & $4.45(3.85,4.76)$ \\
\hline Mean (SEM) & $4.35(0.11)$ & $4.56(0.13)^{* *}$ & $4.47(0.12)$ & $4.48(0.11)^{*}$ & $4.47(0.13)$ & $4.40(0.13)$ \\
\hline $95 \% \mathrm{CI}$ & $4.13-4.58$ & $4.31-4.80$ & $4.24-4.71$ & $4.23-4.70$ & $4.22-4.72$ & $4.16-4.64$ \\
\hline \multicolumn{7}{|l|}{$\operatorname{PSV}(\mathrm{cm} / \mathrm{s})$} \\
\hline $\begin{array}{l}\text { Median (first, } \\
\text { third quartile) }\end{array}$ & $76.8(64.9,95)$ & $77.8(70,87.8)$ & $82.1(62,93)$ & $\begin{array}{c}74.375 \\
(58.2,82.2)\end{array}$ & $74.7(62.2,87.6)$ & $73(57.5,78.1)$ \\
\hline Mean (SEM) & $80.2(4.0)$ & $80.0(4.0)$ & $79.0(4.3)$ & $74.4(3.5)$ & $73.3(3.5)^{*}$ & $70.1(3.5)^{* *}$ \\
\hline $95 \% \mathrm{CI}$ & $7.32-88.0$ & $72.1-87.9$ & $70.6-87.4$ & $67.5-81.3$ & $66.5-80.2$ & $63.3-76.9$ \\
\hline \multicolumn{7}{|l|}{$\operatorname{EDV}(\mathrm{cm} / \mathrm{s})$} \\
\hline $\begin{array}{l}\text { Median (first, } \\
\text { third quartile) }\end{array}$ & $16.7(14.0,21.2)$ & $16.9(14.7,20.8)$ & $16.6(12.2,20.7)$ & $14.8(12.0,20.2)$ & $14.2(12.2,17.1)$ & $11.3(9.3,14.2)$ \\
\hline Mean (SEM) & $17.9(1.3)$ & $17.3(1.2)$ & $16.8(1.2)$ & $15.6(1.1)$ & $14.8(1.1)^{* *}$ & $11.6(0.9)^{* *}$ \\
\hline $95 \% \mathrm{CI}$ & $15.5-20.4$ & $15.0-19.6$ & $14.4-19.2$ & $13.4-17.8$ & $12.6-17.1$ & $9.9-13.3$ \\
\hline \multicolumn{7}{|l|}{ RI } \\
\hline $\begin{array}{l}\text { Median (first, } \\
\text { third quartile) }\end{array}$ & $0.83(0.75,0.90)$ & $0.80(0.75,0.86)$ & $0.79(0.76,0.85)$ & $0.81(0.78,0.85)$ & $0.83(0.80,0.96)$ & $0.89(0.95)$ \\
\hline Mean (SEM) & $0.87(0.04)$ & $0.85(0.03)$ & $0.85(0.04)$ & $0.87(0.04)$ & $0.90(0.04)$ & $0.92(0.03)^{* *}$ \\
\hline $95 \% \mathrm{CI}$ & $0.79,-0.94$ & $0.77-0.92$ & $0.78-0.92$ & $0.79-0.94$ & $0.82-0.98$ & $0.87-0.98$ \\
\hline \multicolumn{7}{|l|}{ PI } \\
\hline $\begin{array}{l}\text { Median (first, } \\
\text { third quartile) }\end{array}$ & $2.45(1.98,3.18)$ & $2.33(1.97,2.68)$ & $2.25(1.96,2.85)$ & $2.33(2.05,2.88)$ & $2.64(2.20,3.48)$ & $3.26(2.77,3.76)$ \\
\hline Mean (SEM) & $4.22(1.05)$ & $3.29(0.71)$ & $3.32(0.67)$ & $3.58(0.83)$ & $3.65(0.69)$ & $3.62(0.50)$ \\
\hline $95 \% \mathrm{CI}$ & $2.17-6.27$ & $1.90-4.68$ & $1.99-4.63$ & $1.96-5.21$ & $2.29-5.01$ & $2.66-4.58$ \\
\hline \multicolumn{7}{|l|}{$\mathrm{MV}(\mathrm{ml} / \mathrm{s})$} \\
\hline $\begin{array}{l}\text { Median (first, } \\
\text { third quartile) }\end{array}$ & $28.4(20.7,34.3)$ & $29.0(19.4,34.6)$ & $28.8(20.4,33.0)$ & $25.9(19.9,32.2)$ & $24.5(16.2,28.7)$ & $22.0(15.5,25.4)$ \\
\hline Mean (SEM) & $27.4(2.4)$ & $27.3(2.2)$ & $26.8(2.3)$ & $25.1(2.1)$ & $23.4(1.9)^{* *}$ & $20.9(1.6)^{* *}$ \\
\hline $95 \%$ CI & $22.6-32.1$ & $23.0-31.5$ & $22.3-31.2$ & $21.1-29.2$ & $19.5-27.2$ & $17.9-23.9$ \\
\hline \multicolumn{7}{|l|}{$\mathrm{BFV}(\mathrm{ml} / \mathrm{min})$} \\
\hline $\begin{array}{l}\text { Median (first, } \\
\text { third quartile) }\end{array}$ & $\begin{array}{c}248.2 \\
(204.3,326.3)\end{array}$ & $\begin{array}{c}262.8 \\
(211.1,365.8)\end{array}$ & $\begin{array}{c}271.3 \\
(190.8,329.2)\end{array}$ & $\begin{array}{c}242.7 \\
(188.4,314.0)\end{array}$ & $\begin{array}{c}218.4 \\
(154.0,273.4)\end{array}$ & $\begin{array}{c}178.2 \\
(136.6,247.1)\end{array}$ \\
\hline Mean (SEM) & $246.3(25.2)$ & $268.2(26.4)$ & $255.4(25.2)$ & $240.4(24.1)$ & $220.8(22.2)$ & $195.3(21.1)^{* *}$ \\
\hline $95 \% \mathrm{CI}$ & $200.6-292.0$ & $220.3-316.1$ & $209.8-301.1$ & $196.8-284.0$ & $180.5-261.1$ & $158.1-232.5$ \\
\hline
\end{tabular}

Hemodynamic parameters measured by ultrasound are shown for the brachial artery. The values represent medians and quartile (first and third), means and SEM and 95\% CI. TS, thermal stimulation; BFV, blood flow volume. ${ }^{*} P<.05,{ }^{* *} P<.01$ versus baseline.

TABLE 3: Summary of hemodynamic parameters.

\begin{tabular}{|c|c|c|c|c|c|c|}
\hline Parameter & Baseline & During TS & $10 \mathrm{~min}$ after TS & 20 min after TS & $30 \mathrm{~min}$ after TS & $40 \mathrm{~min}$ after TS \\
\hline \multicolumn{7}{|l|}{ HR (beats/min) } \\
\hline Median (first, third quartile) & $61(54,64)$ & $57(54,67)$ & $58(54,61)$ & $56(53,61)$ & $56(54,62)$ & $58(53.3,60.5)$ \\
\hline Mean (SEM) & $59.6(1.9)$ & $60.0(2.0)$ & $58.5(1.6)$ & $57.3(1.8)$ & $58.7(1.7)$ & $58(1.8)$ \\
\hline $95 \% \mathrm{CI}$ & $56.0-63.3$ & $56.1-63.8$ & $55.2-61.7$ & $53.9-60.8$ & $55.4-62.0$ & $54.8-61.54$ \\
\hline \multicolumn{7}{|l|}{ Syst BP (mmHg) } \\
\hline Median (first, third quartile) & $115(106,125)$ & $116(109,125)$ & $114(108,127)$ & $118(111,124)$ & $116(113,125)$ & $118.5(112,127)$ \\
\hline Mean (SEM) & $117.3(2.4)$ & $117.9(2.6)$ & $117.5(2.6)$ & $118.9(2.5)$ & $120.4(2.9)$ & $121.9(3.1)^{*}$ \\
\hline $95 \% \mathrm{CI}$ & $113.0-121.5$ & $113.5-122.2$ & $113.2-121.7$ & $114.3-123.6$ & $115.6-125.5$ & $117.1-126.7$ \\
\hline \multicolumn{7}{|l|}{ Dia BP (mmHg) } \\
\hline Median (first, third quartile) & $69(63,75)$ & $66(63,80)$ & $66(62,72)$ & $68(62,78)$ & $69(62,76)$ & $69.5(63.8,77.3)$ \\
\hline Mean (SEM) & $69.8(2.2)$ & $69.9(2.2)$ & $68.1(2.2)$ & $70.6(2.4)$ & $70.7(2.6)$ & $72.1(2.5)$ \\
\hline $95 \%$ CI & $65.5-74.0$ & $65.6-74.2$ & $63.9-72.4$ & $66.0-75.2$ & $65.5-75.8$ & $67.3-76.9$ \\
\hline
\end{tabular}

Blood pressure and heart rate are also shown. The values represent medians and quartile (first and third), means and SEM and 95\% CI. TS, thermal stimulation; HR, heart rate; Syst BP, systolic blood pressure; Dia BP, diastolic blood pressure; CI, confidence interval. ${ }^{*} P<.05,{ }^{* *} P<.01$ versus baseline. 


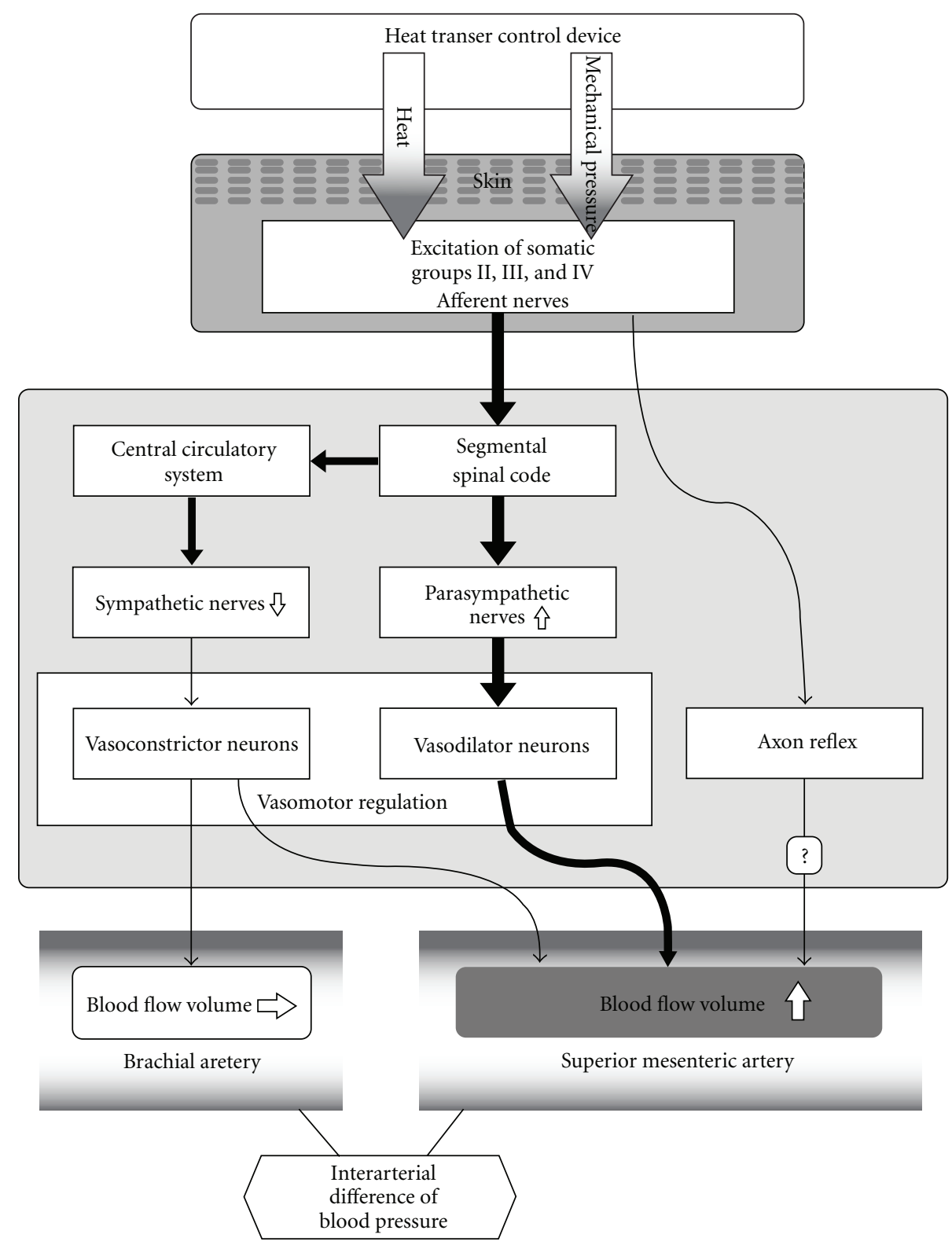

Figure 6: Hypothesis of mechanisms for increasing blood flow volume in SMA compared with BA.

by vasospasm [50]. Chronic mesenteric ischemia usually is caused by atherosclerosis [51]. In these conditions, the pathophysiology is same as the mesenteric ischemia. The treatment of mesenteric ischemia is the reperfusion by drugs or vessel reconstruction. Sometimes vasodilative drugs are selected for conservative treatment [50-52]. We demonstrated the increase of SMA blood flow volume with local thermal therapy in the present study. The treatment of local thermal therapy with HTCD may be useful for mesenteric ischemia to increase the blood flow volume.

When SMA hemodynamics during thermal stimulation was measured by ultrasound, the acceleration of intestinal peristalsis was observed along with an increase in bloodflow volume. Thus, thermal stimulation not only increases the blood-flow volume, but also improves intestinal motility. Abdominal thermal therapy may be useful for patients with low SMA blood flow, paralytic ileus or chronic constipation. In the future, we hope to study the effect of thermal stimulation on patients with such disorders.

Moxibustion is often combined with acupuncture; however, in the West it is not often used because of the odor from the burning moxa. HTCD can heat the target area uniformly without any odor or the dangers associated with a fire. Thus, abdominal thermal therapy with an HTCD may be useful for patients with intestinal disorders instead of moxibustion. We would like to undertake further studies to clarify the effect of local thermal stimulation, for not only the abdomen but also for other areas. 
In conclusion, we could measure the effect of local thermal stimulation quantitatively with an HTCD and highresolution ultrasound. Thermal stimulation of the paraumbilical region could increase blood flow in the SMA 20 min after stimulation in healthy subjects.

\section{Funding}

Special Coordination Funds for Promoting Science and Technology from the Japanese Ministry of Education, Culture, Sports, Science and Technology.

\section{Acknowledgment}

The authors would like to thank all the participants and especially Ms Setsu Watanabe for drawing Figure 6.

\section{References}

[1] S. Joos, B. Brinkhaus, C. Maluche et al., "Acupuncture and moxibustion in the treatment of active Crohn's disease: a randomized controlled study," Digestion, vol. 69, no. 3, pp. 131-139, 2004.

[2] S. Joos, N. Wildau, R. Kohnen et al., "Acupuncture and moxibustion in the treatment of ulcerative colitis: a randomized controlled study," Scandinavian journal of gastroenterology, vol. 41, no. 9, pp. 1056-1063, 2006.

[3] S. P. Yun, W. S. Jung, S. U. Park et al., "Effects of moxibustion on the recovery of post-stroke urinary symptoms," American Journal of Chinese Medicine, vol. 35, no. 6, pp. 947-954, 2007.

[4] C. Tei, Y. Horikiri, J.-C. Park et al., "Effects of hot water bath or sauna on patients with congestive heart failure: acute hemodynamic improvements by thermal vasodilation," Journal of Cardiology, vol. 24, no. 3, pp. 175-183, 1994 (Japanese).

[5] C. Tei, Y. Horikiri, J.-C. Park et al., "Acute hemodynamic improvement by thermal vasodilation in congestive heart failure," Circulation, vol. 91, no. 10, pp. 2582-2590, 1995.

[6] C. Tei, "Thermal therapy for congestive heart failure: estimation by TEI index," Journal of Cardiology, vol. 37, pp. 155-159, 2001.

[7] S. Biro, A. Masuda, T. Kihara, and C. Tei, "Clinical implications of thermal therapy in lifestyle-related diseases," Experimental Biology and Medicine, vol. 228, no. 10, pp. 1245-1249, 2003.

[8] R. S. Greenberg, "The effects of hot packs and exercise on local blood flow," Physical Therapy, vol. 52, no. 3, pp. 273-278, 1972.

[9] A. Masuda, Y. Koga, M. Hattanmaru, S. Minagoe, and C. Tei, "The effects of repeated thermal therapy for patients with chronic pain," Psychotherapy and Psychosomatics, vol. 74, no. 5, pp. 288-294, 2005.

[10] J. Leppaluoto, P. Huttunen, J. Hirvonen, A. Vaananen, M. Tuominen, and J. Vuori, "Endocrine effects of repeated sauna bathing," Acta Physiologica Scandinavica, vol. 128, pp. 467470, 1986.

[11] A. Masuda, M. Nakazato, T. Kihara, S. Minagoe, and C. Tei, "Repeated thermal therapy diminishes appetite loss and subjective complaints in mildly depressed patients," Psychosomatic Medicine, vol. 67, no. 4, pp. 643-647, 2005.
[12] A. Michalsen, R. Lüdtke, M. Bühring, G. Spahn, J. Langhorst, and G. J. Dobos, "Thermal hydrotherapy improves quality of life and hemodynamic function in patients with chronic heart failure," American heart journal, vol. 146, no. 4, pp. 728-733, 2003.

[13] M. Umehara, A. Yamaguchi, S. Itakura et al., "Repeated Waon therapy improves pulmonary hypertension during exercise in patients with severe chronic obstructive pulmonary disease," Journal of Cardiology, vol. 51, no. 2, pp. 106-113, 2008.

[14] M. Giovanni, The Practice of Chinese Medicine: The Treatment of Diseases With Acupuncture and Chinese Herbs, Churchill Livingstone, Edinburgh, UK, 1994.

[15] X. R. Cheng and K. Cheng, "Survey of studies on the mechanism of acupuncture and moxibustion treating diseases abroad," Zhongguo Zhen Jiu, vol. 28, no. 6, pp. 463-467, 2008 (Chinese).

[16] H. G. Wu, Y. Shi, W. Zhang, S. Zhou, and H. R. Liu, "Advances and thinking about prevention and treatment of inflammatory bowel diseases by acupuncture and moxibustion," Zhongguo Zhen Jiu, vol. 26, no. 6, pp. 454-458, 2006 (Chinese).

[17] A. O. Freire, G. C. M. Sugai, M. M. Blanco, A. Tabosa, Y. Yamamura, and L. E. A. M. Mello, "Effect of moxibustion at acupoints Ren-12 (Zhongwan), St-25 (Tianshu), and St36 (Zuzanli) in the prevention of gastric lesions induced by indomethacin in Wistar rats," Digestive Diseases and Sciences, vol. 50, no. 2, pp. 366-374, 2005.

[18] J. Kjeldsen and O. B. Schaffalitzky de Muckadell, "Assessment of disease severity and activity in inflammatory bowel disease," Scandinavian Journal of Gastroenterology, vol. 28, no. 1, pp. 19, 1993.

[19] M. J. Perko, "Duplex ultrasound for assessment of superior mesenteric artery blood flow," European Journal of Vascular and Endovascular Surgery, vol. 21, no. 2, pp. 106-117, 2001.

[20] G. L. Moneta, D. C. Taylor, W. S. Helton, M. W. Mulholland, and D. E. Strandness Jr., "Duplex ultrasound measurement of postprandial intestinal blood flow: effect of meal composition,” Gastroenterology, vol. 95, no. 5, pp. 1294-1301, 1988.

[21] A. Erden, T. Cumhur, and T. Ölçer, "Superior mesenteric artery Doppler waveform changes in response to inflammation of the ileocecal region," Abdominal Imaging, vol. 22, no. 5, pp. 483-488, 1997.

[22] M. F. Byrne, M. A. Farrell, S. Abass et al., "Assessment of Crohn's disease activity by Doppler sonography of the superior mesenteric artery, clinical evaluation and the Crohn's disease activity index: a prospective study," Clinical Radiology, vol. 56, no. 12, pp. 973-978, 2001.

[23] A. Siǧirci, T. Baysal, R. Kutlu, M. Aladağ, K. Saraç, and H. Harputluoğlu, "Doppler sonography of the inferior and superior mesenteric arteries in ulcerative colitis," Journal of Clinical Ultrasound, vol. 29, no. 3, pp. 130-139, 2001.

[24] C. F. Dietrich, M. Jedrzejczyk, and A. Ignee, "Sonographic assessment of splanchnic arteries and the bowel wall," European Journal of Radiology, vol. 64, no. 2, pp. 202-212, 2007.

[25] S. Takashima, N. Ogasawara, S. Maruyama, A. Komiya, T. Seki, and T. Yambe, "Development of precise heat transfer control devises for thermal therapy," in Proceedings of the 2nd International Forum on Heat Transfer (IFHT '08), pp. 171-177, Tokyo, Japan, September 2008.

[26] S. C. Jiang, N. Ma, H. J. Li, and X. X. Zhang, "Effects of thermal properties and geometrical dimensions on skin burn injuries," Burns, vol. 28, no. 8, pp. 713-717, 2002.

[27] E. Y. K. Ng and L. T. Chua, "Comparison of one- and twodimensional programmes for predicting the state of skin burns," Burns, vol. 28, no. 1, pp. 27-34, 2002. 
[28] U. Gembruch, "Assessment of the fetal circulatory state in uteroplacental insufficiency by Doppler ultrasound: which vessels are the most practicable?" Ultrasound in Obstetrics \& Gynecology, vol. 8, no. 2, pp. 77-81, 1996.

[29] R. W. Gill, "Measurement of blood flow by ultrasound: accuracy and sources of error," Ultrasound in Medicine and Biology, vol. 11, no. 4, pp. 625-641, 1985.

[30] F. Van Bel, P. H. T. Van Zwieten, G. L. Guit, and J. Schipper, "Superior mesenteric artery blood flow velocity and estimated volume flow: duplex Doppler US study of preterm and term neonates," Radiology, vol. 174, no. 1, pp. 165-169, 1990.

[31] P. N. Burns and C. C. Jaffe, "Quamtitative flow measurements with Doppler ultrasound: techniques, accuracy, and limitations," Radiologic Clinics of North America, vol. 23, no. 4, pp. 641-657, 1985.

[32] K. J. W. Taylor and S. Holland, "Doppler US. Part I. Basic principles, instrumentation, and pitfalls," Radiology, vol. 174, no. 2, pp. 297-307, 1990.

[33] M. I. Qamar and A. E. Read, "Effects of exercise on mesenteric blood flow in man," Gut, vol. 28, no. 5, pp. 583-587, 1987.

[34] K. Ray-Chaudhuri, S. A. Ryder, T. Thomaides, and C. J. Mathias, "The relationship between blood flow and pulsatility index in the superior mesenteric artery at rest and during constrictor stimuli in normal subjects," Journal of Clinical Ultrasound, vol. 22, no. 3, pp. 149-160, 1994.

[35] S. Uchida and H. Hotta, "Acupuncture affects regional blood flow in various organs," Evidence-Based Complementary and Alternative Medicine, vol. 5, no. 2, pp. 145-151, 2008.

[36] A. Tabosa, Y. Yamamura, E. Romão Forno, and L. E. A. M. Mello, "A comparative study of the effects of electroacupuncture and moxibustion in the gastrointestinal motility of the rat," Digestive Diseases and Sciences, vol. 49, no. 4, pp. 602-610, 2004.

[37] M. Iwa, M. Matsushima, Y. Nakade, T. N. Pappas, M. Fujimiya, and T. Takahashi, "Electroacupuncture at ST-36 accelerates colonic motility and transit in freely moving conscious rats," American Journal of Physiology, vol. 290, no. 2, pp. G285G292, 2006.

[38] D. Luo, S. Liu, X. Xie, and X. Hou, "Electroacupuncture at acupoint ST-36 promotes contractility of distal colon via a cholinergic pathway in conscious rats," Digestive Diseases and Sciences, vol. 53, no. 3, pp. 689-693, 2008.

[39] C. H. Chen, Acupuncture: A Comprehensive Text, Eastland Press, Seattle, Wash, USA, 1981.

[40] H. Tsuru and K. Kawakita, "Acupuncture on the blood flow of various organs measured simultaneously by colored microspheres in rats," Evidence-Based Complementary and Alternative Medicine, vol. 6, no. 1, pp. 77-83, 2009.

[41] M. J. Joyner and J. R. Halliwill, "Sympathetic vasodilatation in human limbs," Journal of Physiology, vol. 526, no. 3, pp. 471480, 2000.

[42] I. C. Roddie, J. T. Shepherd, and R. F. Whelan, "The vasomotor nerve supply to the skin and muscle of the human forearm," Clinical Science, vol. 16, pp. 67-74, 1957.

[43] B. J. Prout, "Independence of the galvanic skin reflex from the vasoconstrictor reflex in man," Journal of Neurology Neurosurgery and Psychiatry, vol. 30, no. 4, pp. 319-324, 1967.

[44] I. L. Gibbins and J. L. Morris, "Pathway specific expression of neuropeptides and autonomic control of the vasculature," Regulatory Peptides, vol. 93, no. 1-3, pp. 93-107, 2000.

[45] B. H. Dennis, R. C. Eberhart, G. S. Dulikravich, and S. W. Radons, "Finite-element simulation of cooling of realistic 3-D human head and neck," Journal of Biomechanical Engineering, vol. 125, no. 6, pp. 832-840, 2003.
[46] S. Maruyama, A. Komiya, T. Yambe, and N. Nakasato, "Brain mapping method utilizing rapid cooling probe," in Proceedings of the 17th International Symposium on Transport Phenomena, 2006, CD-ROM 1-D-I-4:3.

[47] S. Takashima, S. Maruyama, H. Takeda, J. Okajima, A. Komiya, T. Seki et al., "Study on bio-heat transfer in living body by using abdominal heating controller," in Proceedings of the 44th National Heat Transfer Symposium, vol. A151, p. 2, 2007, (in Japanese).

[48] H. H. Pennes, "Analysis of tissue and arterial blood temperatures in the resting human forearm," Journal of Applied Physiology, vol. 1, no. 2, pp. 93-122, 1948.

[49] T. Samaras, A. Christ, and N. Kuster, "Effects of geometry discretization aspects on the numerical solution of the bioheat transfer equation with the FDTD technique," Physics in Medicine and Biology, vol. 51, no. 11, pp. N221-N229, 2006.

[50] A. Mitsuyoshi, K. Obama, N. Shinkura, T. Ito, and M. Zaima, "Survival in nonocclusive mesenteric ischemia: early diagnosis by multidetector row computed tomography and early treatment with continuous intravenous high-dose prostaglandin $\mathrm{E}_{1}$," Annals of Surgery, vol. 246, no. 2, pp. 229-235, 2007.

[51] P. L. Kozuch and L. J. Brandt, "Review article: diagnosis and management of mesenteric ischaemia with an emphasis on pharmacotherapy," Alimentary Pharmacology and Therapeutics, vol. 21, no. 3, pp. 201-215, 2005.

[52] J. H. van Bockel, R. H. Geelkerken, and M. N. Wasser, "Chronic splanchnic ischaemia," Best Practice and Research: Clinical Gastroenterology, vol. 15, no. 1, pp. 99-119, 2001. 


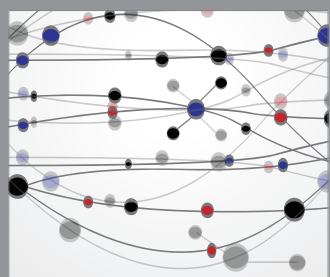

The Scientific World Journal
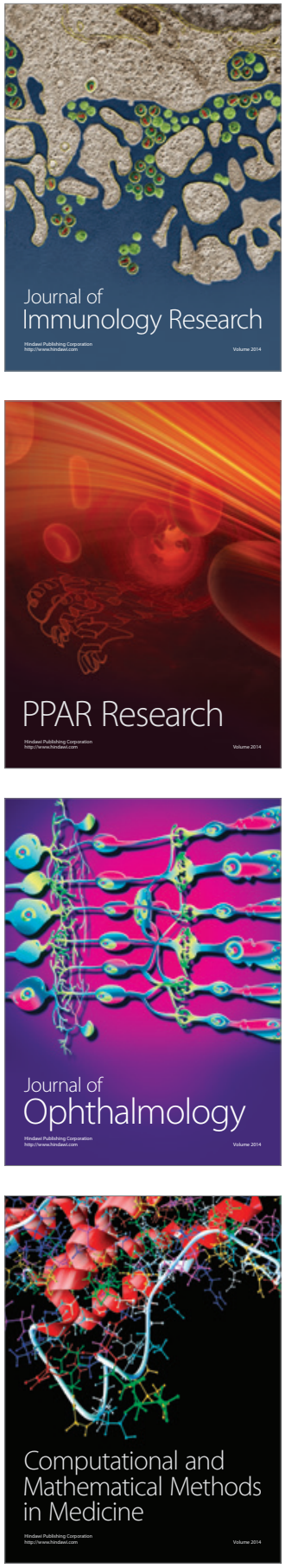

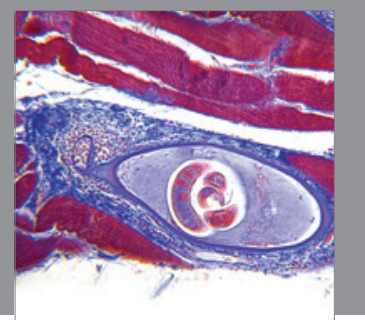

Gastroenterology

Research and Practice
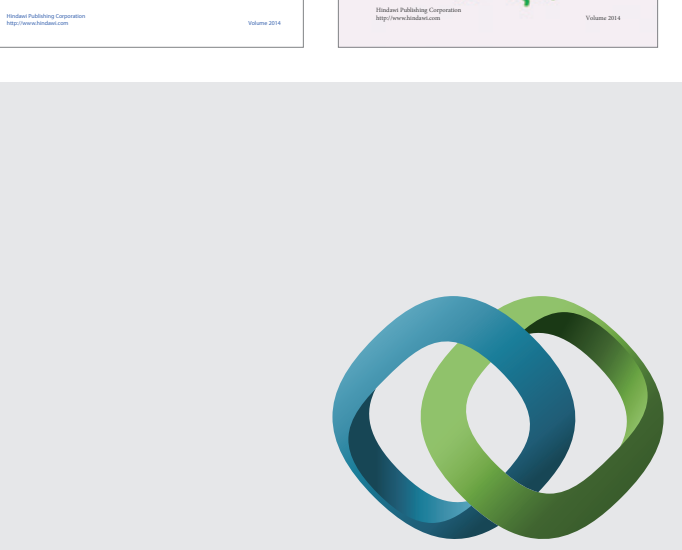

\section{Hindawi}

Submit your manuscripts at

http://www.hindawi.com
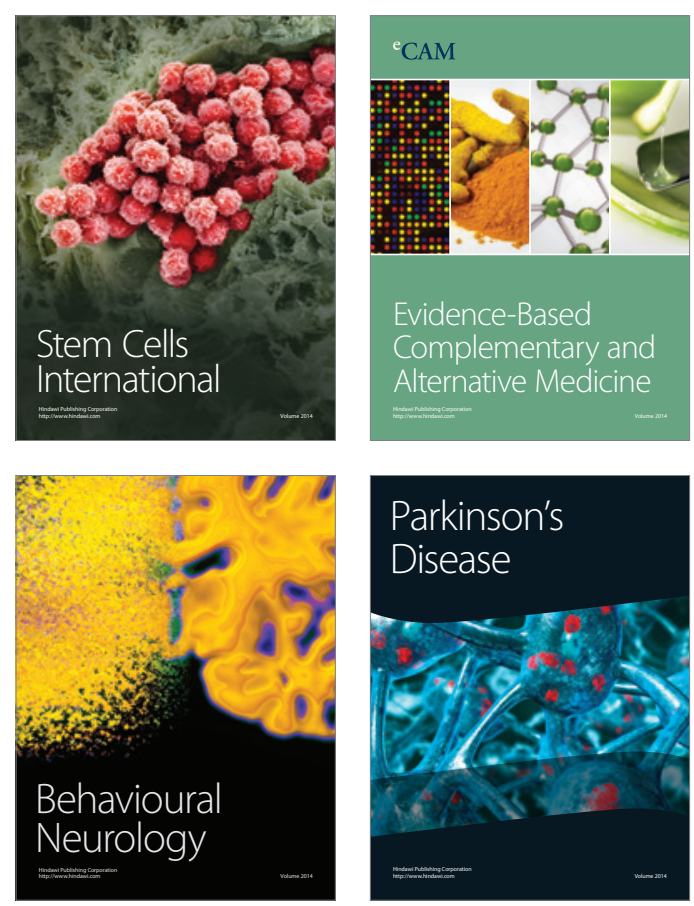

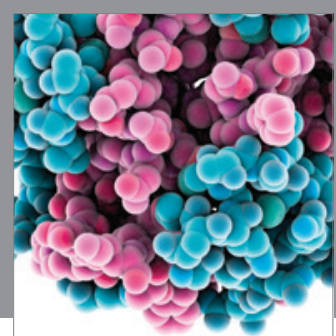

Journal of
Diabetes Research

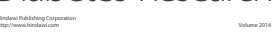

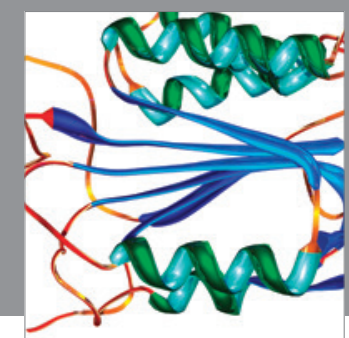

Disease Markers
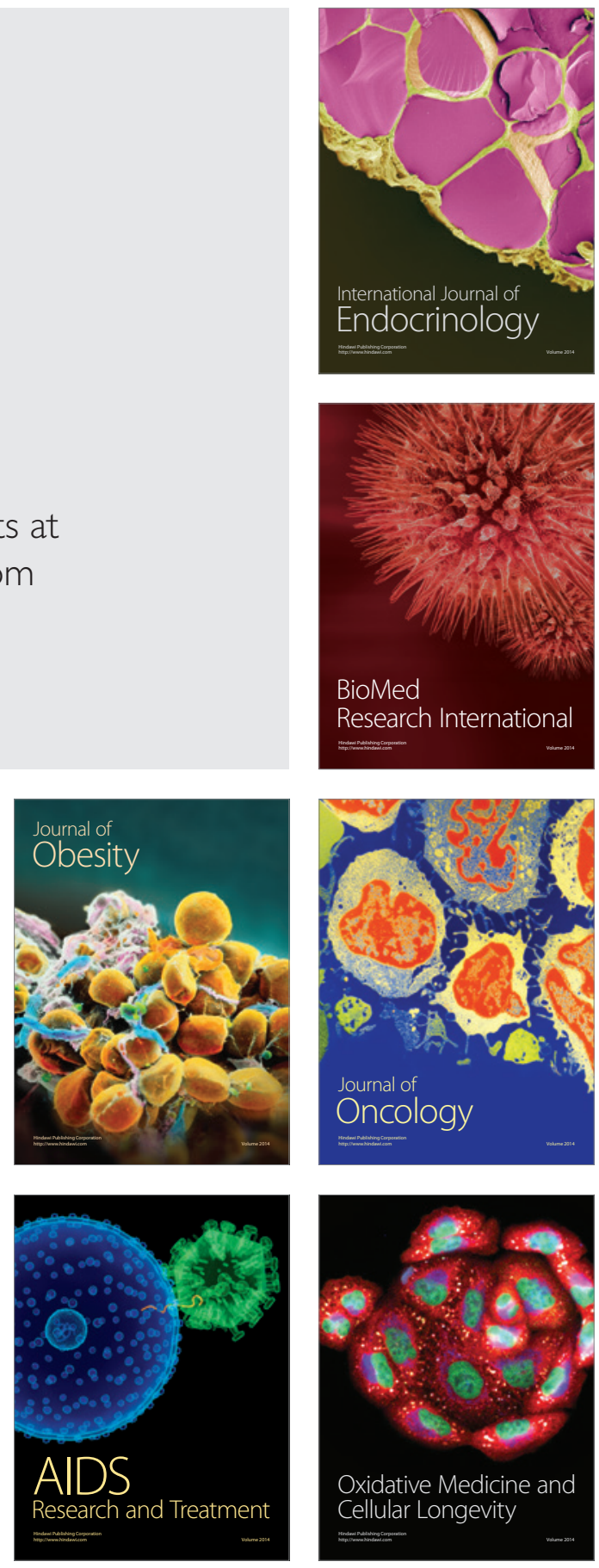